\title{
An Exploration of Prevalence of Repetitive Stress Injuries among Computer Operators in Nigeria
}

\author{
A.A. Kayode \\ Computer Science Department \\ Osun State College of \\ Technology \\ Esa-Oke, Nigeria.
}

\author{
J.A. Adewale \\ Computer Science Department \\ Osun State College of \\ Technology \\ Esa-Oke, Nigeria.
}

\author{
N.T.A. Lawal \\ Computer Science Department \\ Osun State College of \\ Technology \\ Esa-Oke, Nigeria.
}

\begin{abstract}
Computers have revolutionized education and the workplace, people are doing excellent jobs using computer to process and analyse data, type and format documents, design graphics, etc. However, there has been far too little attention paid to the dangers of Repetitive Stress Injuries (RSIs) among computer operators who use computers often and extensively. There are simple safety skills and understandings that can be easily incorporated into computer usage.
\end{abstract}

Six hundred (600) questionnaires were personally administered to computer operators and other computer-users ranging from Students, Lecturers, Bankers, Civil Servants to Health Workers in the major cities of South - West of Nigeria. The result of the survey was analysed using SPSS and descriptive statistical techniques.

The study shows that computer operators spend more hours working with computers than other computer-users. $83.4 \%$ of these computer operators spend more than 6 hours, working with computers at a stretch per day, very few $(16.6 \%)$ observe breaks in-between. The study also reveals that RSIs are more prevalent among computer operators than other computerusers. Larger percentage of computer operators suffers some forms of RSI syndrome than other computer-users who rarely suffer more than one syndrome. Precautionary measures how these syndromes can be reduced are also highlighted in this study.

\section{Keywords}

RSIs, computer operators, computer-users, survey, prevalence

\section{INTRODUCTION}

Repetitive Stress Injuries (RSIs), also called cumulative trauma disorder (CTD), are a potentially debilitating conditions resulting from overusing the hands to perform a repetitive task, such as typing, clicking a mouse, or writing. Anyone who uses a computer regularly is at risk and should know about RSIs. Unfortunately, most people are uninformed and do not understand what RSI is or how serious it can be.

In simple medical terms, repetitive stress injury (RSI) is defined as a cumulative trauma disorder (CTD) arising from prolonged repetitive, forceful, or awkward hand movements. The results are eye strain, damage to muscles, tendons, and nerves of the neck, shoulder, forearm, and hand, which can cause pain, weakness, and numbness.

Over the years, computer-related RSIs have increasingly plagued the modern office workplace, debilitating hundreds of thousands of workers, causing pain, impairment and, in some cases, disability [1]. With the increase in computer dependency in various walks of life, individual who spends more period of time on the computer are prone to a greater risk of developing RSIs and it has been observed that individual suffering from RSIs tends to be less productive.

Take for instance, a computer operator who works with computers on a daily basis and partakes in a number of activities relative to such operations; entering data, formatting documents, aiding in fixing computer problems and at times supervising others using computers. This paper focuses on an exploration of prevalence of the RSIs among computer operators in Nigeria.

According to [2], RSI is a serious tragedy because it has drastically disrupted the lives and livelihoods of many people all over the world. There have been a lot of research work done in the western world and even in Nigeria, but no specific study is available in the Nigerian context, especially in regards to computer operators, who are at maximum risk of developing the disorder because of their work demands and working environment. Computer operators are group of persistent computer users that spend more time working with computers for an average of 8 to 10 hours per day and this make them liable to having RSIs syndrome. They need to be informed that this career threatening syndrome is prevalent among them because of their prolonged use of computer systems, when they are informed, then they can take proper mindful efforts to reduce the symptoms.

\section{LITERATURE REVIEW}

Several studies have been done in order to examine the incidence of RSIs among computers users as we. Some of them are discussed in this section. In the study conducted by [3], the author highlighted two factors that majorly cause RSIs; which are individual (intrinsic) and workplace (extrinsic) and also provide list of symptoms resulting from repetitive work.

In [4], various musculoskeletal pains associated with the use of computer systems in Nigeria were examined. The target of this study was student population. Six Federal University campuses were surveyed across the nation. The study showed that low back pain, neck pain and shoulder pain are the common disorders complaints among the users and the cause of the pains was attributed to bad ergonomics among the users.

Also in [5], the incidence of Repetitive Strain Injury among computer users in Nigeria was investigated. The investigation focused on the general computer users from various walks of life, ranging from banking sector, civil service, educational sector, health sector to private sector. The result of the investigation showed that there are significant relationships between duration of computer usage, type of chair used, type and size of monitor used and the incidence of RSI. 
Moreover, in [6], a survey of computer users in University of Benin, Nigeria was conducted on the issue of Occupational Overuse Syndrome (OOS). The data for his study was collected by means of a structured questionnaire administered to staff and student of the university. Here, results showed that low back pain, neck pain, headache, shoulder pain and eyestrain, are the most prevalent OOS symptoms/pains. He recommended that there is need for computer workplaces to improve on their designs towards finding a lasting solution to the hazardous problem.

[7] discussed the relationship between leisure-time physical activity and work related RSIs. The result indicated that being physically active during leisure time is associated with decreased risk of RSI, adding another potential health benefit to participation in leisure-time physical activity.

In [8], the awareness and incidence of RSI in d computer graphic industries were examined using data collected from computer graphic designers across various graphic firms in Lagos State. Their study showed that most of the graphic designers fail to maintain good posture while doing their graphic designing on the computer. It was concluded that the overall lack of knowledge about RSI on the part of the graphic designers was the major cause of the syndrome among them.

There is dearth of literature that examined the effects of Repetitive Stress Injuries as related specifically to computer operators which indeed makes the study significant. The study intends therefore to fill the research gaps with respect to prevalence of RSIs among computer operators.

\section{METHODOLOGY}

The study was carried out using a total of 600 self administered questionnaires. Two groups of respondents (computer operators and other computer-users) in the major cities of South-West of Nigeria were surveyed between February 2013 and August 2014. Out of these respondents, there were 300 computer operators and 300 other computerusers viz: students, lecturers, bankers, civil servants and health workers. Though the focus of the study is to explore the prevalent of RSIs among computer operators but other computer-users have to be surveyed so as to ascertain that RSIs are more prevalent among computer operators than other computer-users.

The questionnaire enquires such information like: bio-data, RSI syndrome suffered, demographics, frequency use of computer, prevalent of RSIs. Data collected from the respondents were analyzed using SPSS and descriptive statistical technique (frequency tables and charts).

\section{RESULT}

\subsection{Demographic of Respondents}

Six hundred questionnaires were administered to two groups of respondents. Computer operators were named Group A and other computer-users named Group B. out of these 600 questionnaires 300 were administered to group $\mathrm{A}$.

Table 1 shows the demographic (age and gender) information of Group A. $72.7 \%$ of the surveyed population of computer operators is younger people between ages 18 to 30 years, this account for the fact that majority of computer operators are Secondary School leavers, awaiting admission, young graduates and young people who have acquired some level of skills in Electronic Data Processing (EDP) and graphic design.
Also, most computer operators $(63.3 \%)$ are male showing the peculiarity of Nigerian culture which place more responsibly upon male children than the female ones.

Table 1. Demographic information of Group A

\begin{tabular}{|l|l|l|l|}
\hline Age (Years) & Frequency & Percent & $\begin{array}{l}\text { Cumulative } \\
\text { percent }\end{array}$ \\
\hline $18-30$ & 218 & 72.7 & 72.7 \\
\hline $31-45$ & 75 & 25.0 & 97.7 \\
\hline $46-65$ & 7 & 2.3 & 100 \\
\hline Total & 300 & 100 & \\
\hline Gender & & & \\
\hline Male & 190 & 63.3 & 63.3 \\
\hline Female & 110 & 36.7 & 100.0 \\
\hline Total & 300 & 100.0 & \\
\hline
\end{tabular}

Similarly, Table 2 presents the demographic (age and gender) information of Group B. Group B consists of other computerusers viz: students, lecturers, bankers, civil servants and health workers.

Table 2. Demographic information of Group B

\begin{tabular}{|l|l|l|l|}
\hline $\begin{array}{l}\text { Age } \\
\text { (Years) }\end{array}$ & Frequency & Percent & $\begin{array}{l}\text { Cumulative } \\
\text { percent }\end{array}$ \\
\hline $18-30$ & 125 & 41.7 & 41.7 \\
\hline $31-45$ & 111 & 37.0 & 78.7 \\
\hline $46-65$ & 64 & 21.3 & 100 \\
\hline Total & 300 & 100 & \\
\hline Gender & & & \\
\hline Male & 178 & 59.3 & 59.3 \\
\hline Female & 122 & 40.7 & 100.0 \\
\hline Total & 300 & 100.0 & \\
\hline
\end{tabular}

\subsection{Duration of Computer Usage}

The questionnaires administered to the respondents carefully look at the duration (hours) spend with computer at a stretch per day for each of the groups. Table 3 presents the hours spend with computer by group A. It was found that largest percentage $(83.4 \%)$ of computer operators works with computers for more than 6 hours at a stretch per day to meet deadlines. They responded that once they start working with their computers they are immerse in their work to the extent that they forget about eating and that they do not take breaks in between. Very few of them cannot afford working up to six hours without taking breaks in between.

Also, table 4 shows how often other computer-users work with their computers. Very few of them (3.7\%) spend more than six hours working with their computers. From their response, most of them argued they don't have any deadline to meet and that they work in their own pace. 
Table 3. Duration of computer usage for Group A

\begin{tabular}{|l|l|l|l|}
\hline Hours & Frequency & Percent & $\begin{array}{l}\text { Cumulative } \\
\text { percent }\end{array}$ \\
\hline $1-2$ & 106 & 35.3 & 35.3 \\
\hline $2-3$ & 136 & 45.3 & 80.6 \\
\hline $4-6$ & 47 & 15.7 & 96.3 \\
\hline $7-8$ & 9 & 3.0 & 99.3 \\
\hline$>8$ & 2 & 0.7 & 100.0 \\
\hline Total & 300 & 100.0 & \\
\hline
\end{tabular}

Table 4. Duration of computer usage for Group B

\begin{tabular}{|c|c|c|c|}
\hline Hours & Frequency & Percent & $\begin{array}{c}\text { Cumulative } \\
\text { percent }\end{array}$ \\
\hline $1-2$ & 0 & 0.0 & 0.0 \\
\hline $2-3$ & 7 & 2.3 & 2.3 \\
\hline $4-6$ & 43 & 14.3 & 16.6 \\
\hline $7-8$ & 185 & 61.7 & 78.3 \\
\hline$>8$ & 65 & 21.7 & 100.0 \\
\hline Total & 300 & 100.0 & \\
\hline
\end{tabular}

\subsection{Occurrence of RSI among the Respondents}

Tables 5 and 6 show the occurrence of RSIs among the Respondents viz. computer operators (Group A) and other computer-users (Group B) respectively. Respondents were asked to indicate RSIs syndrome they experience when working with computers. The questionnaire take into consideration only those common RSI syndromes reported from literatures. These are: Low back pain, Shoulder pains, Finger tingling, Wrist pain, Elbow pain, Eyes strain, and Neck pain. It was gathered that individual respondent experience more than one of these RSIs syndrome at any time or the other when working with computer.

\subsection{Prevalence of RSI among Computer Operators}

Figure 1 presents the Comparison between duration of computer usage by Groups A and B. from the diagram it can be observed that computer operators spend longer hours working with computer than other computer-users this is because they have to meet deadlines.

Similarly, figure 2 shows that RSI syndromes are more prevalent among computer users that other computer-users this is because the former spend more hours working with computer without taking breaks in between.

\section{SUGGESTIONS FOR SUCCESSFUL PREVENTION OF RSIS}

We suggest that computer operators who suffer from severe and persistent RSI syndromes should consult their doctors or health providers and tarry not. A combination of early diagnosis and a few precautions can reduce the damage to their body, minimize pain, and maximize the enjoyment they get from life.

The key to treating an RSI is to avoid the activity or position that is causing the injury. We equally advised that computer operators to take breaks in between when they are working with computers and to work in an ergonomically correct position. Proper computer placement, correct typing and sitting positions and well-designed furniture will make the computer environment ergonomic and prevent RSIs.

In order to have an ergonomically friendly and correct working environment, the following guidelines as prescribed by [9] should also be properly observed:

a. The type and position of a chair used by computer operators must not only be seen to be restful but also seen to be adjustable to various positions in height, side and back support.

b. Computer operators should position their legs in a conducive manner, having their feet flattened on the floor and the leg at a right angle to the hips. More so, foot rest to be used by operators can be an adjustable type to accommodate the size and height of individuals.

c. An adjustable back support could be provided to sustain the lower back of the operators.

d. While typing or clicking mouse, the wrist should be positioned properly. More importantly, a wrist rest can make the wrist positioning suitable for operators. The operators should also keep their elbows at a right angle to the upper arms. Furthermore, the elbow should not be kept at too much distance to the body.

e. The keyboard height also plays a significant role in provision of conducive use of computer system by operators. Adjustment of keyboard height should be considered, which can suit usability by operators irrespective of their heights.

f. Computer screen has to be properly placed with respect to the users seating position. Furthermore, the screen resolution should be normalised and possibly set at brightness suitable for human sight. The use of screen protective cover is also advised to lessen the inherent hazardous effects of screen brightness on operators' eyes. Screen guard should be used where necessary.

Table 5: Stress Injuries reported by group A

\begin{tabular}{|c|c|c|c|c|c|}
\hline RSI & Never (\%) & Minor (\%) & Average (\%) & Severe (\%) & $* *$ Total Affected (\%) \\
\hline Low back pain & 15.0 & 22.3 & 25.7 & 37.0 & 85.0 \\
\hline Shoulder pain & 20.0 & 24.0 & 23.0 & 33.0 & 80.0 \\
\hline Finger tingling & 6.0 & 73.7 & 13.0 & 7.3 & 94.0 \\
\hline Wrist pain & 26.3 & 40.3 & 15.0 & 18.3 & 73.7 \\
\hline
\end{tabular}




\begin{tabular}{|l|l|l|l|l|l|}
\hline Elbow pain & 19.7 & 23.0 & 25.7 & 31.7 & 80.3 \\
\hline Eyes strain & 33.3 & 46.3 & 14.7 & 5.7 & 66.7 \\
\hline Neck pain & 16.7 & 21.3 & 26.0 & 36 & 83.3 \\
\hline \multicolumn{7}{|c|}{$* *$ Never Neglected } \\
\hline
\end{tabular}

Table 6: Stress Injuries reported by group B

\begin{tabular}{|c|c|c|c|c|c|}
\hline RSI & Never (\%) & $\begin{array}{c}\text { Minor } \\
(\boldsymbol{\%})\end{array}$ & Average (\%) & Brutal (\%) & **Total Affected (\%) \\
\hline Low back pain & 67.0 & 20.0 & 10.0 & 3.0 & 33.0 \\
\hline Shoulder pains & 74.3 & 13.7 & 6.7 & 5.3 & 25.7 \\
\hline Finger tingling & 89.3 & 5.0 & 3.7 & 2.0 & 10.7 \\
\hline Wrist pain & 79.7 & 10.3 & 7.0 & 3.0 & 20.3 \\
\hline Elbow pain & 80.0 & 9.0 & 7.3 & 3.7 & 20.0 \\
\hline Eyes strain & 79.3 & 16.7 & 2.3 & 1.7 & 20.7 \\
\hline Neck pain & 64.3 & 22.7 & 9.0 & 4.0 & 35.7 \\
\hline
\end{tabular}

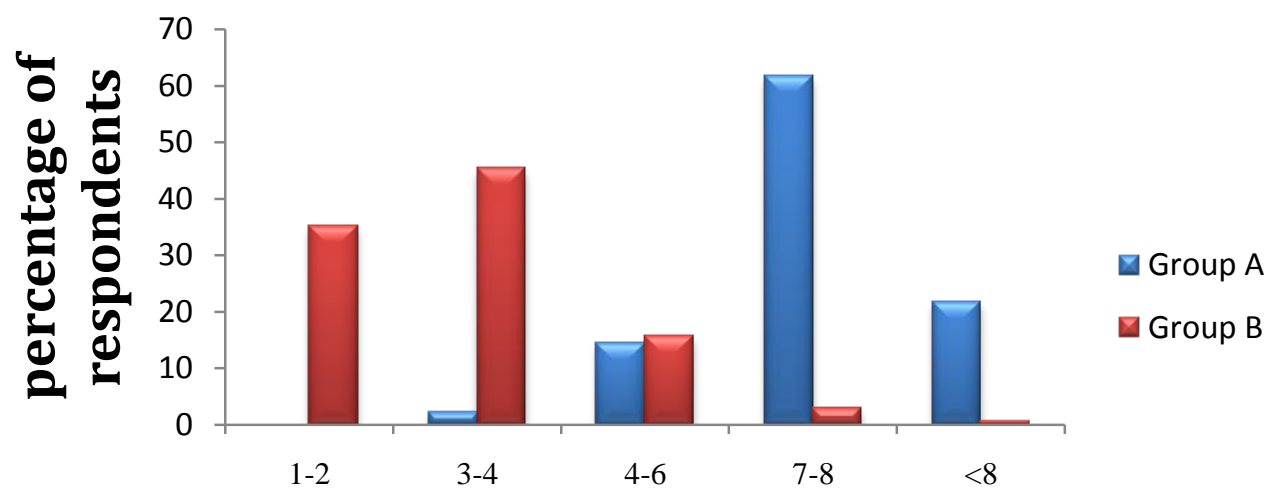

Hours of computer usage

Figure 1. Comparison between hours spend with computer by Groups A and B

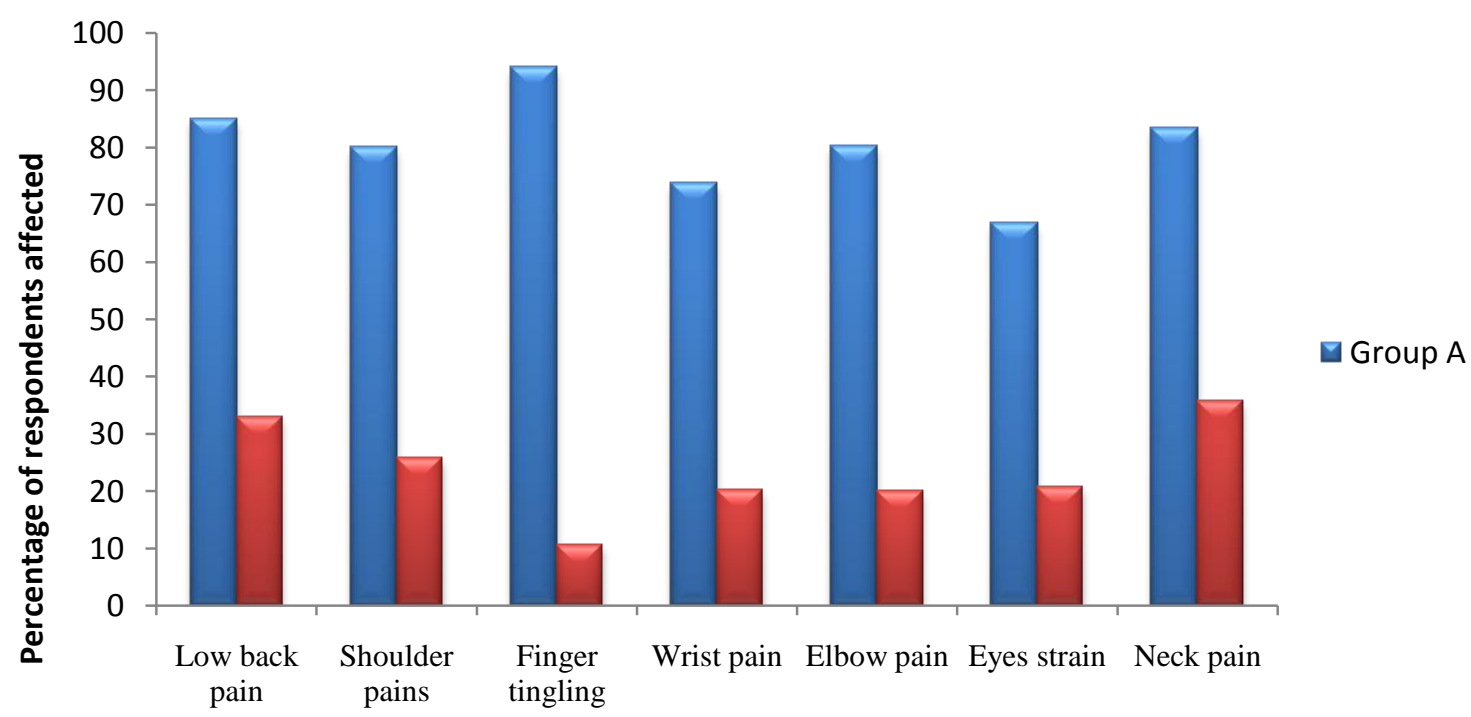

Figure 2: Comparison between occurrences of RSI between and Groups A and B 


\section{CONCLUSION AND FUTURE RESEARCH}

From the study conducted, it has been established that computer operators spend longer hours working with computers which makes them prone to severe and persistent pains. It is also noted that the pressure to meet deadlines and the nature of their working are also responsible for the higher percentage of the syndromes they suffer in comparison to other computer-users. Therefore, RSIs are seen to be more prevalent among computer operators than other computerusers. Also precautions for successful prevention of RSIs have been suggested which if properly adhered to can reduce RSIs syndrome suffered by them.

Future research will be towards sentisizing the computer operators of the risk involved in spending longer hours with computers without taking intermittent breaks.

\section{ACKNOWLEDGEMENT}

We thank the authors whose works are cited and referenced in this paper for providing us with the foundation with which we build our work upon.

\section{REFERENCES}

[1] Vivienne, G. and Norman J. 2001. The Typing Injury FAQ, Motion-Based Ergonomics Keyboard Retraining Available on http://www.tifaq.org/ergonomics.html (Accessed on 29/08/2014).

[2] Nivedita 2007. The Effect of Stretching and Strengthening exercises as a treatment Program for RSI of Upper Extremity in Computer Professionals, Rajiv Gandhi University of Health Sciences, Karnakata, Banglore, Unpublished.

[3] Melhorn, J. M. 2004. Repetitive Stress Injuries: Fact or fiction: Current Opinion in Orthopedics: 251-258.

[4] Adedoyin R. A, Idowu B.O, Adagunodo R. E \& Idowu P.A. 2005. Musculoskeletal pain associated with the use of computer systems in Nigeria", IOS Press Amsterdam, The Netherlands, the Netherlands. Vol. 13 issue 2, p125130.

[5] Olabiyisi O, Akingboye Y, Abayomi-Alli A, Izilien F, Adeleke I. 2013. An Investigation of the Incidences of Repetitive Strain Injury among computer Users in Nigeria. Available on http://www.arxiv.org/pdf/ 1308.5841 (Accessed on 29/05/2014).
[6] Allen E. 2007. Occupational Overuse Syndrome (OOS): a recurring problem in the Computer Industrially developing Countries (IDCs) a case study at University of Benin, Benin City Nigeria." HFES Journal, Ergonomics Australia Vol. 21, Number 3 pp. 10-18

[7] Ratzlaff, C. R., Gillies, J. H. and Koehoorn M. W. 2007. Work-related Repetitive Strain Injury and leisure-time physical activity, Volume 57 Issue 3, pp. 495 - 500.

[8] Sunday, T., Dibia, I. and Bayonle S. 2012. The awareness and incident of RSI in the computer graphic industries in Lagos. J. Information and Knowledge Management. Volume 2 No. 8: page 61-70

[9] Singh, G.M. 2010. Tips to maintain proper posture for computer use. eMedinewS Daily available at http://issue.emedinews.in/rchive/07_11_10.html (accessed 29/05/2014)

\section{AUTHOR'S PROFILE}

Kayode, Aderonke A. received both B. Sc. and M. Sc. in Computer Science from Obafemi Awolowo University, IleIfe, Nigeria in 2003 and 2011 respectively. She is a member of Computer Professional Registration Council of Nigeria (MCPN). She is a Lecturer in the Department of Computer Science, Osun State College of Technology, Esa-Oke, Nigeria. She is currently pursuing her $\mathrm{Ph}$. D in Computer Science, she has published in reputable journals. Her research areas include Health Informatics, Artificial Intelligence and Information storage and retrieval systems.

Adewale, Joseph A. received B. Tech. in computer science from Ladoke Akintola Universty, Ogbomoso, Nigeria. He also obtained M. Sc. in Multimedia Application and Virtual Environments from University of Sussex, Falmer Brighton, UK. His research areas include Computer animation, virtual environments, computer vision and HCI. He is a Lecturer in the Department of Computer Science, Osun State College of Technology, Esa-Oke, Nigeria.

Lawal, Nurudeen T.A. received B. Tech. in computer science from Federal Universty of Technology Akure, Nigeria. He also obtained M. Sc. in Information Technology Management for Business from University of Greenwich, UK. His research areas include soft computing, ICT, HCI and AI. $\mathrm{He}$ is a member of Computer Professional Registration Council of Nigeria (MCPN). He is also a Lecturer in the Department of Computer Science, Osun State College of Technology, Esa-Oke, Nigeria. 